\title{
Influence of Biological Variations and Sample Handling on Measured Microalbuminuria in Diabetic Patients
}

\author{
I. Vermes ${ }^{1}$ and P.F.M.J. Spooren ${ }^{2}$ \\ Departments of Clinical Chemistry ${ }^{1}$ and Internal Medicine, ${ }^{2}$ Medical Spectrum Twente, \\ Enschede, The Netherlands
}

\begin{abstract}
Five immunochemical assays for determining low concentrations of albumin were investigated. These were a radioimmunoassay (RIA); turbidimetric immunoassays (TIA) both according to end-point measuring principle on a Cobas Fara and Hitachi 717 analysers, and according to kinetic measuring principle on a Turbitimer instrument; and a nephelometric immunoassay (NIA). All achieved the analytical goal necessary for optimal patient care. The correlations between the albumin concentrations measured with the different techniques were very good. In vitro glycation of albumin did not influence albumin concentrations measured by the five assays. Urine albumin excretion measured over 3 consecutive days showed considerable day-to-day
\end{abstract}

variation. This was highest for spot-urine specimens and significantly lower for $24 \mathrm{~h}$ and timed-overnight samples. Variation of storage temperature (room temperature, $4^{\circ} \mathrm{C},-20^{\circ} \mathrm{C}$ ), time (up till 3 months), and $\mathrm{pH}$ (within the range $\mathrm{pH} 5-8$ ) of the urine samples did not change significantly the measured albumin concentrations. Different sample preparations (vortex-mixing, centrifugation, and thawing) had no influence on the measured albumin concentration. In conclusion, a maximum standardization of the collection of timed-overnight urine samples for screening and $24 \mathrm{~h}$ urine samples for confirmation of microalbuminuria during 3 consecutive days is more crucial than the choice of the immunological technique. (c) 1992 Wiley-Liss, Inc.

Key words: microalbuminaria, diabetes mellitus, screening, variation source of, sample handling, temperature, glycation of albumin

\section{INTRODUCTION}

Microalbuminuria both in type 1 (insulin-dependent) and type 2 (non-insulin-dependent) diabetic patients has been shown to predict increased mortality, not only from renal origin but also from cardiovascular disease (1-3). Therefore screening of diabetic patients for microalbuminuria has become part of routine diabetes care (4). However, there is still some discussion about which urine sample should be measured (5). To compare various studies is difficult, because not only different methods of specimen collection are used, but also different sample-handling, assay conditions, and expression of urine albumin excretion (6-16). Therefore this study was undertaken to compare the usefulness of different methods of specimen collection ( $24 \mathrm{~h}$ collection, timed-overnight specimen, first-morning sample, and spot-urine specimen) in the same diabetic patients during 3 consecutive days. In addition, the influence of sample handling (storage temperature, time, $\mathrm{pH}$, and sample preparation) and technique of determination was studied in urine of diabetic patients. In an attempt to explain some contradictions from the literature the influence of in vitro glycation of albumin on the microalbumin determination was investigated separately.

\section{MATERIALS AND METHODS}

\section{Assays}

Microalbuminuria was determined with the following immunoassays: a) Radioimmunoassay (RIA): Albumin Double Antibody RIA Kit, Diagnostic Products Corp., Los Angeles, CA; b) Turbidimetric Immunoassay (TIA): according to the endpoint measuring principle with antisera purchased from Orion Diagnostica, Espoo, Finland don a Cobas Fara centrifugal analyser (Hoffman-La Roche, Basel, Switzerland) and with antisera from Boehringer Mannheim Gmbh., Germany (Tinaquant Albumin kit) on a Hitachi 717 analyser; furthermore according to kinetic measurement principle by using Turbiquant Albumin Kit on a Turbitimer instrument (Behringwerke AG, Marburg, Germany); and c) Nephelometric Immunoassay (NIA) by using Behring Reagent Kit on a Laser Nephelometer (Behringwerke AG, Marburg, Germany). All these assays were performed according to the instructions of the manufacturers.

Received February 28, 1992; accepted June 10, 1992.

Address reprint requests to Dr. I. Vermes, Department of Clinical Chemistry, Medical Spectrum Twente, P.O. Box 50000, 7500KA Enschede, The Netherlands. 


\section{In Vitro Glycation of Albumin}

Human serum albumin (HSA) and fresh frozen plasma (FFP) samples were incubated for 11 days at room temperature with $0.5 \mathrm{M}$ glucose in the presence of $1 \mathrm{~g} / \mathrm{L}$ sodium azide by continuous rotation. Thereafter the samples were dialysed against destillated water for $48 \mathrm{~h}$ at $4^{\circ} \mathrm{C}$ (dialysis tubing, Sigma Chemical Co., St. Louis, MO). After dialysis the glucose concentration was $<0.1 \mathrm{mmol} / \mathrm{L}$. The fructosamine concentrations were 132 and $57 \mu \mathrm{mol} / \mathrm{L}$ before glycation and 1134 and $335 \mu \mathrm{mol} / \mathrm{L}$ after glycation measured in HSA and FFP samples, respectively.

\section{Specimen Collection}

Timed-overnight urine specimen were collected from 296 type 1 and type 2 diabetic patients consecutively attending the outpatient diabetic clinic. The albumin concentrations of all collections were separately measured with the four immunoassays and the results were expressed as $\mathrm{mg} / \mathrm{L}$.

In addition, eight patients with known microalbuminuria were asked to collect all urine samples during 3 consecutive days. No patients were older than 60 years. They were free of major systemic complications of diabetes and of overt kidney disease. Patients were asked to avoid vigorous exercise during the time of collection, and they received detailed written and verbal instruction about the collection. Urine was collected in plastic containers without additive. Collections began immediately after an initial evening void at bedtime, the time of which was recorded. All urine produced overnight was collected in a separate plastic bottle on which the patient recorded the beginning and ending-times (Timed-overnight urine specimen). The morning sample was collected in a separate container and the time of the void was also noted. The first sample after the morning specimen was collected in a third bottle (Spot-urine specimen). All urine during the day was collected in a fourth container. The patients were asked to store the bottles with urine on a cool place until the delivery of the four containers to the outpatient clinic the morning after the collection. The volumes of all collections were separately measured and aliquots were prepared. The $24 \mathrm{~h}$ specimen was a combination of all samples collected during the $24 \mathrm{~h}$ period and corrected in volume and time. All of these samples were measured with the TIA method on a Cobas Fara analyser. Albumin excretion rate (AER) was expressed as mg albu$\min / 24 \mathrm{~h}$ for a $24 \mathrm{~h}$ sample and $\mu \mathrm{g}$ albumin/min for a timedovernight sample, and the albumin concentration in a spot-urine sample as $\mathrm{mg}$ albumin $/ \mathrm{mmol}$ creatinine.

\section{Sample Handling}

Aliquots were stored at room temperature for 7 days, at $4^{\circ} \mathrm{C}$ for 3 weeks and at $-20^{\circ} \mathrm{C}$ for 3 months. Determinations with the TIA method on a Cobas Fara analyser were done after different time intervals as indicated in Figure 3 . The speci- mens were vortex-mixed and centrifuged $(1500 \mathrm{~g}, 10 \mathrm{~min})$ before assay. In a second series of aliquots the $\mathrm{pH}$ of the urine samples was adjusted to $\mathrm{pH} 4,5,6,7$, and 8 . Aliquots were stored at $-20^{\circ} \mathrm{C}$ and analysed 0,1 , and 4 weeks after adjustment. These results were compared with albumin concentrations obtained with fresh unadjusted samples. A third series of aliquots was kept at $-20^{\circ} \mathrm{C}$ for a maximum of 7 days, but the samples were equilibrated daily to room temperature and either vortex-mixed or vortex-mixed and centrifuged. Measurements of all 12 samples were done on day 0 and on day 7 .

\section{Data Evaluation and Statistical Methods}

Sensitivity (lower detection limit) was defined as the albumin concentration corresponding to the response of the mean +2 SD response of the zero standard, determined by replicate analysis $(n=20)$. Intrer-assay precision $(C V)$ was estimated by measuring control samples in duplicate at three concentrations in ten runs. Intra-assay precision $(\mathrm{CV})$ was calculated by replicate analysis $(n=20)$ of the control samples at three concentrations in one run. Analytical recoveries were estimated by serial dilutions of the standards, and the percentage recoveries were calculated. Method comparisons were performed using regression analysis according to Passing and Bablok (17).

\section{RESULTS}

\section{Assay Characteristics}

The five assays showed approximately the same order of analitical sensitivity (Table 1). The working-ranges varied significantly. The large dynamic range makes TIA-assays more easy to perform but has no consequences for their analytical performance. Intra- and inter-assay precisions and analytical recoveries were comparable for all methods (Table 1).

\section{Method Comparisons}

The correlations between the albumin concentrations measured with the different techniques were very good (Fig. 1) $(r=0.985,0.994,0.997$, and 0.904 Cobas Fara vs. RIA, Hitachi 717, Turbitimer, and NIA, respectively). Owing to the practical advantages of the TIA method performed on a Cobas Fara analyser (operating cost and technical skill), all routine measurements were performed according to this method.

\section{Effect of Glycation}

There were no significant differences when untreated or glycated albumine samples were measured with all five assays (Table 2).

\section{Effect of Sample-Choice}

Urine albumine excretion measured over 3 consecutive days showed considerable day-to-day variations in each patient 
TABLE 1. Comparison of the Analytical Performance of Different Microalbumine Assays

\begin{tabular}{|c|c|c|c|c|c|}
\hline & \multicolumn{3}{|c|}{ TIA } & \multirow[b]{2}{*}{ NIA } & \multirow[b]{2}{*}{ RIA } \\
\hline & Cobas Fara & Hitachi & Turbitimer & & \\
\hline $\begin{array}{l}\text { Sensitivity }(\mathrm{mg} / \mathrm{L}) \\
\quad(\mathrm{n}=20)\end{array}$ & 2.5 & 3 & 3 & 0.2 & 0.5 \\
\hline $\begin{array}{l}\text { Working range }(\mathrm{mg} / \mathrm{L}) \\
(\mathrm{n}=10)\end{array}$ & $2.5-80$ & $3-400$ & $3-3,500$ & $0.2-54$ & $0.5-60$ \\
\hline \multicolumn{6}{|l|}{ Precision (CV), \% } \\
\hline \multicolumn{6}{|l|}{ Intra-assay $(n=20)$} \\
\hline Low level ${ }^{\mathrm{a}}$ & 3.5 & 5.5 & 2.5 & 3.3 & 2.9 \\
\hline Intermediate ${ }^{b}$ & 1.8 & 1.5 & 1.4 & 1.7 & 3.2 \\
\hline High level $^{c}$ & 2.4 & 1.1 & 1,4 & 3.1 & 2.8 \\
\hline \multicolumn{6}{|l|}{ Inter-assay $(n=10)$} \\
\hline Low level ${ }^{\mathrm{a}}$ & 7.4 & 10.3 & 8.0 & 8.0 & 3.5 \\
\hline Intermediate $^{\mathrm{b}}$ & 3.7 & 1.7 & 5.1 & 3.2 & 2.7 \\
\hline High level $^{c}$ & 2.4 & 2.4 & 7.4 & 2.9 & 2.3 \\
\hline Anal. recovery, $\%$ & $96-105$ & $92-102$ & $88-104$ & $98-104$ & $96-102$ \\
\hline
\end{tabular}

${ }^{2}$ Low level: $4-6 \mathrm{mg} / \mathrm{L}$.

'Intermediate level: $30-35 \mathrm{mg} / \mathrm{L}$.

'High level: $170-200 \mathrm{mg} / \mathrm{L}$.

Fig. 2). The highest biological day-to-day variation was observed when spot urine specimens were measured (CV 34\%). The day-to-day $\mathrm{CV}$ was significantly lower when albumin excretion was measured in $24 \mathrm{~h}$ and timed-overnight samples ( $\mathrm{CV}$ of $14 \%$ and $19 \%$, respectively).

\section{Effect of Sample-Handling}

Storage time and temperature did not have a significant influence on measured albumin concentration (Fig. 3). There was no difference between albumin concentrations measured freshly or after $\mathrm{pH}$ adjustment between $\mathrm{pH} 5$ to 8 . This holds true both for the directly measured samples and those assayed after 1 and 4 weeks. Only adjustment to $\mathrm{pH} 4$ caused a significant decrease (36\% and $43 \%$ after 1 and 4 weeks, respectively) in the measured albumin concentrations (Fig. 4). Different sample preparations did not have significant influence on the measured albumin concentration when urine samples $(\mathrm{N}=12)$ were directly measured $(21.9 \pm 12.6 \mathrm{mg} / \mathrm{L})$ or stored at $-20^{\circ} \mathrm{C}$ for 7 days $(22.0 \pm 12.7 \mathrm{mg} / \mathrm{L})$ or stored at $-20^{\circ} \mathrm{C}$ but daily thawed during a week, vortex-mixed and analysed directly $(23.1 \pm 12.8 \mathrm{mg} / \mathrm{L})$ or after centrifugation $(23.5 \pm 13.0 \mathrm{mg} / \mathrm{L})$.

\section{DISCUSSION}

Immunological assays are used to measure low concentrations of albumin in urine because dye-binding or protein precipitation techniques are insensitive and nonspecific. All five immunological assays tested here achieved the analytical goal necessary for optimal patient care (6). On basis of analytical evaluation there is no reason to reject one of them and a choice can be made based on practical points (operational costs, required technical skill, and logistics). Our choice was an end-point TIA measurement performed on a Cobas Fara analyser because we found this assay inexpensive, simple, and rapid to perform, and it fits into our laboratory organisation. The choice of the sample and the way of the handling of the sample is much more disputable (6-16). There is a general agreement that $24 \mathrm{~h}$ collection is the most reliable specimen to confirm the presence of microalbuminuria $(6,14,16)$. However our results, obtained by collecting urine during 3 consecutive days, emphasize the need for repeated collection and measurement of AER even with $24 \mathrm{~h}$ specimens. The same holds true when timed-overnight sample collection is used. In accordance with literature $(14,16)$ we found correlation between $24 \mathrm{~h}$ and overnight collected samples but the mean levels of the same patients were lower in the overnight collected samples. This may be a result of posture, exercise, diet, etc. during the day-time. Therefore, theoretically, the timed-overnight urine sample is the most reliable specimen to follow microalbuminuria in diabetic patients. However, the measured results do not support this view (Fig. 2) $(14,16)$. Both collection techniques are inconvenient for patients and both methods are dependent of the accuracy of the patient. Timed-overnight urine collection is very sensitive to a wrong notition of time, but throwing away a sample happens rarely. On the contrary, $24 \mathrm{~h}$ urine sample is less sensitive to time but the loss of a part of the collection is greater, because the patient forgets the collection during the day. Therefore, the spot-urine sample is potentially interesting as an alternative (8). However the very high day-to-day variation in spot-urine samples implies that interpretation of these results does require caution.

Urine is often stored at room temperature or at $4^{\circ} \mathrm{C}$ for a few days by the patient or at $-20^{\circ} \mathrm{C}$ for long periods by the laboratory. However the literature shows contradictory reports on the effects of storage temperature, time, and other variables in sample-handling. A number of publications showed 

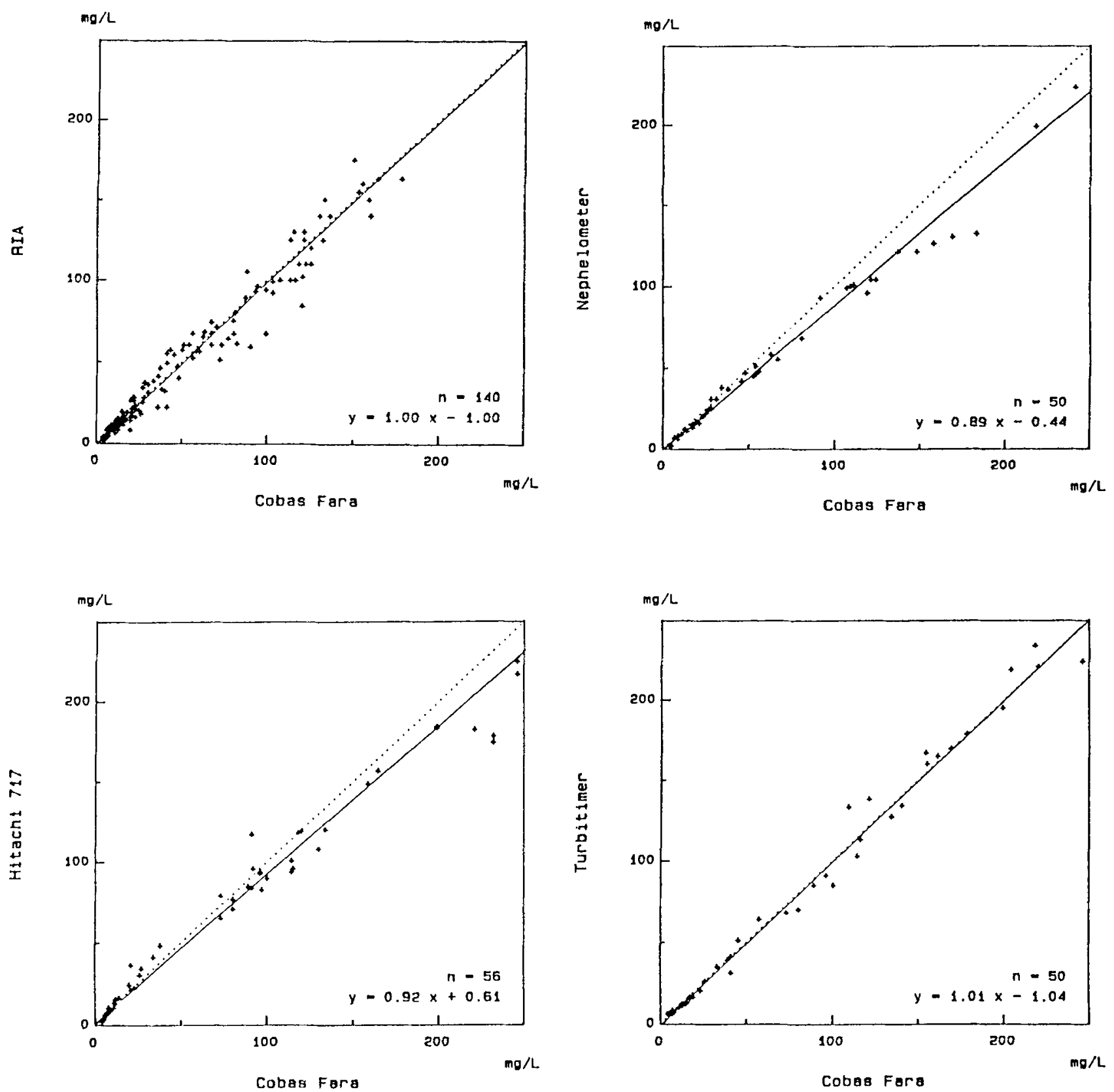

Fig. 1. Correlation between the five immunochemical measurements of urine albumin concentration. Correlation coefficients are given in the text.

a significant decrease of albumin concentration in frozen samples $(11,13,15)$, while others did not find significant effects $(9,12)$. Storage at room temperature for 1 week or at $4^{\circ} \mathrm{C}$ for 3 weeks caused no significant changes $(13,15)$. It has been suggested also that urine $\mathrm{pH}$ is important in the formation of precipitate leading to a decreased albumin concentration in urine samples $(10)$. However we and others $(11,13)$ did not find any effect of $\mathrm{pH}$ in the normal clinical range. The same controversy can be seen on sample preparation such as thawing, vortex-mixing, and centrifugation $(5,9,10,12)$. We did not find a significant influence of these technical manipulations on measured microalbuminuria.

One could speculate that these technical discrepancies are due to the heterogeneity of urine albumin present in diabetic patients (18). It is well documented in literature that the protein composition in urine of patients with diabetes mellitus is different due to the non-enzymatic glycation of protein $(19,20)$. Glycation of a protein could change the specific epitope of the molecule responsible for the antigen-antibody specificity. In addition, glycation could be altered by stor- 
TABLE 2. Effect of Glycation on the Measured Albumin Concentrations With Five Different Assays ${ }^{\mathrm{a}}$

\begin{tabular}{|c|c|c|c|c|c|}
\hline & \multicolumn{5}{|c|}{ Albumin concentration (mg/L) } \\
\hline & \multicolumn{3}{|c|}{ TIA } & \multirow[b]{2}{*}{ NIA } & \multirow[b]{2}{*}{ RIA } \\
\hline & Cobas Fara & Hitachi & Turbitimer & & \\
\hline \multicolumn{6}{|c|}{ Human Serum Albumin } \\
\hline Untreated & 51.6 & 58.3 & 49.6 & 51.8 & 46.1 \\
\hline Glycated & 49.8 & 60.3 & 50.3 & 52.6 & 49.8 \\
\hline \multicolumn{6}{|c|}{ Fresh Frozen Plasma } \\
\hline Untreated & 18.1 & 27.4 & 15.8 & 22.4 & 15.5 \\
\hline Glycated & 20.1 & 23.6 & 16.6 & 21.7 & 14.0 \\
\hline
\end{tabular}

${ }^{a}$ Results are means of four measurements.

age, sample-handling, etc. Therefore, we compared five immunoassays with five different antisera to measure HSA and FFP samples before and after in vitro non-enzymatic glycation (Table 2). We did not find significant differences in the measured albumin concentrations between the glycated and the non-glycated samples, although the fructosamine concentrations as an indication of the glycated albumin increased approximately by a factor of 2.5 .

In conclusion, based on the results presented here, timedovernight-urine collection during 3 consecutive days is our choice to screen microalbuminuria in diabetic patients. We prefer $24 \mathrm{~h}$ samples collected during 3 consecutive days to confirm the observation. The relatively high day-to-day variation during both ways of collection emphasize the need for maximum standardization of the collection (exercise, diet, etc.). It is preferable to measure albumin within 3 weeks when urine is stored at $4^{\circ} \mathrm{C}$, but it can also be done within 3 months if urine is stored at $-20^{\circ} \mathrm{C}$. Sample preparation such as $\mathrm{pH}$ (between $\mathrm{pH}$ 5-8), vortex-mixing, and centrifugation did not influence the measured microalbuminuria, but in practice maximum technical standardization is preferable. According to our observations, a maximum standardization of the collection of timed-overnight urine samples for screening and $24 \mathrm{~h}$ urine samples for conformation of microalbuminuria during 3 consecutive days is more crucial than the choice of the immunological technique.

\section{ACKNOWLEDGMENTS}

We acknowledge Mr. H. Tietema, Hoechst Holland NV, Behring Diagnostica, Amsterdam, and Mr. J. Kunst, Boehringer Mannheim Nederland BV, Almere for supplying the kits for microalbumin determinations. We thank Ms. J. Schonewille for her valuable technical assistance.
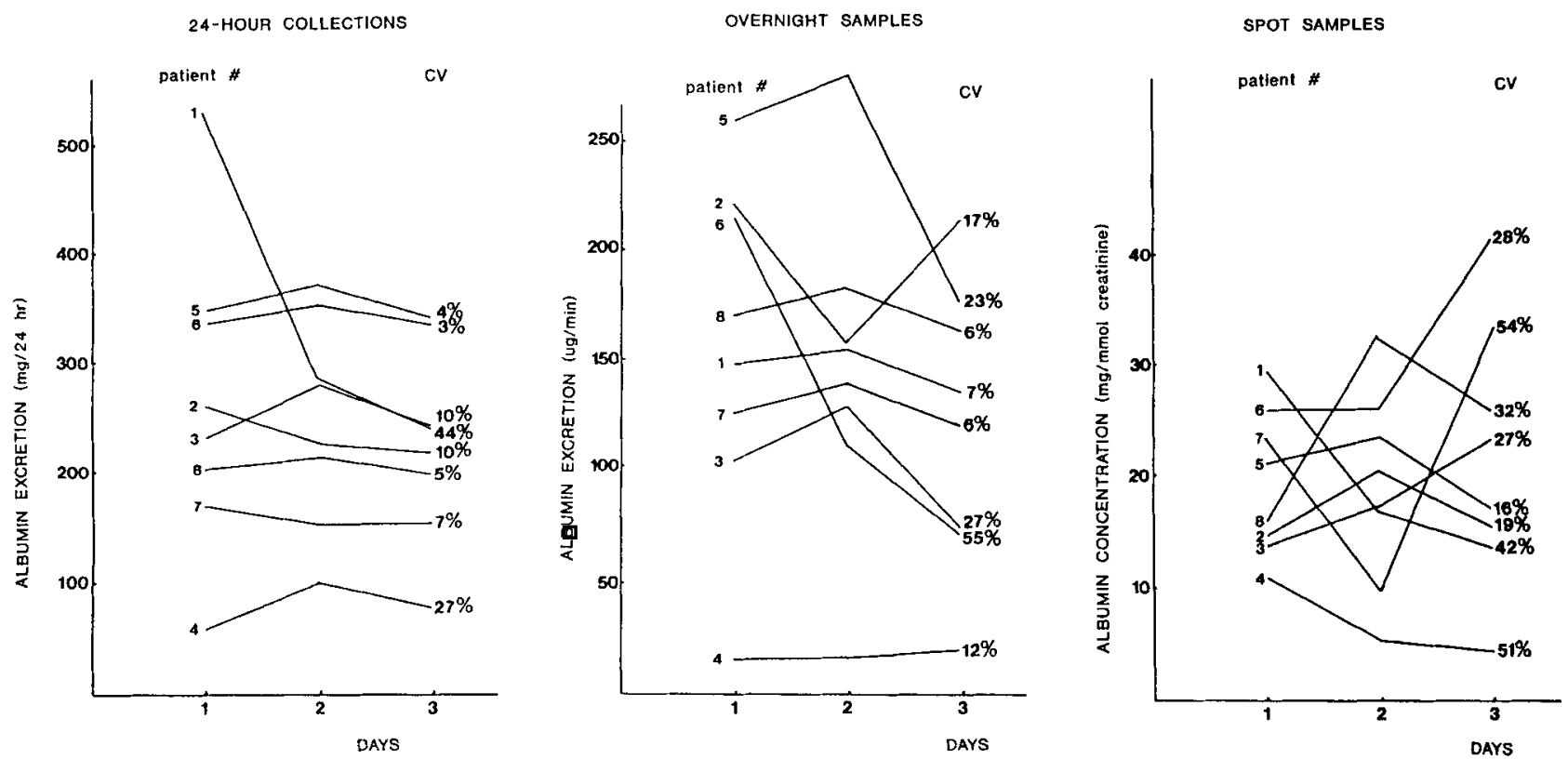

Fig. 2. Day-to-day variations of urine albumin excretion in eight diabetic patients with known microalbuminuria. 

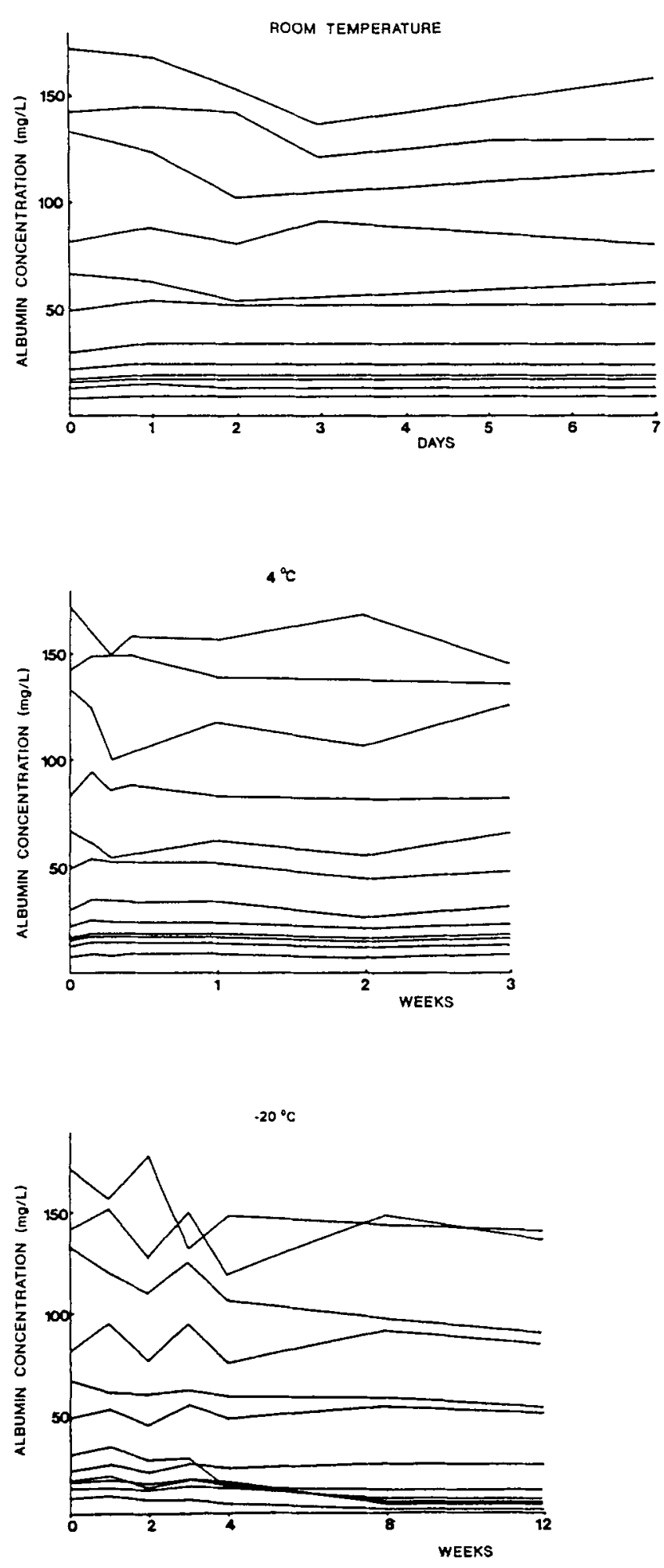

Fig. 3. Effects of storage temperature and time on measured albumin concentrations in urine samples of 12 diabetic patients.

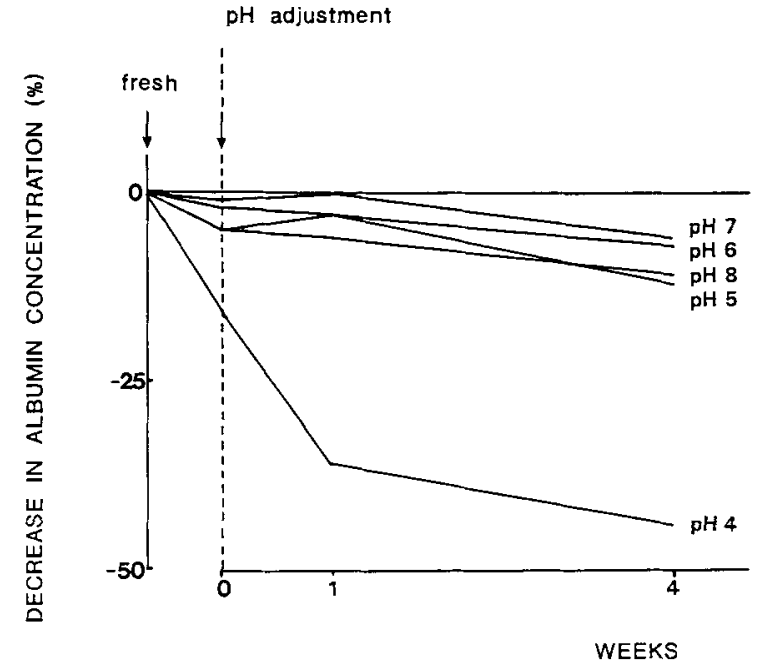

Fig. 4. Effects of pH on measured albumin concentrations in urine samples. Albumin concentrations of ten urine samples were measured freshly after void, directly after $\mathrm{pH}$ adjustment, and 1 and 4 weeks after storage at $-20^{\circ} \mathrm{C}$.

\section{REFERENCES}

1. Viberti GC, Jarrett RJ, Mahmud U, Hill RD: Argyropoulos A, Keen $\mathrm{H}$ : Microalbuminuria as a predictor of clinical nephropathy in insulindependent diabetes mellitus. Lancet 1:1430-1432, 1982.

2. Mogensen CE: Microalbuminuria predicts clinical proteinuria and early mortality in maturity-onset diabetes. N Engl J Med 310:356-360, 1984.

3. Yudkin JS, Forrest RD, Jackson CA: Microalbuminuria as predictor of vascular disease in non-diabetic subjects: Islingtoon Diabetes Survey. Lancet 2:530-533, 1988.

4. Mogensen CE: Management of diabetic renal involvement and disease. Lancet 1:867-869, 1988.

5. Rowe DJF, Dawnay A, Watts GF: Microalbuminuria in diabetes mellitus: Review and recommendations for the measurement of albumin in urine. Ann Clin Biochem 27:297-312, 1990.

6. Jarrett RJ, Viberti GC: Risk of nephropathy in diabetes mellitus: Problems of methodology and terminology. Diabetologia 28:181, 1985.

7. Cowell CT, Rogers S, Silink M: First morning urinary albumin concentration is a good predictor of 24-hour urinary albumin excretion in children with Type 1 (insulin dependent) diabetes. Diabetologia 29:97-99, 1986.

8. Nathan DM, Rosenbaum C, Protasowicki VD: Single-void urine samples can be used to estimate quantitative microalbuminuria. Diabetes Care 10:414-418, 1987.

9. Silver AC, Dawnay A, Landon J: Specimen preparation for assay of albumin in urine. Clin Chem 33:199-200, 1987.

10. Townsend JC, Sadler WA, Shanks GM: The effect of storage $\mathrm{pH}$ on the precipitation of proteins in deep frozen urine samples. Ann Clin Biochem 24:112-112, 1987.

11. Erman A, Rabinov M, Rosenfeld J: Albumin determination in frozen urines-underestimated results. Clin Chim Acta 174:255-262, 1988.

12. Giampietro $\mathrm{O}$, Miccoli $R$, Clerico A, et al.: Urinary albumin excretion in normal subjects and in diabetic patients measured by a radioimmunoassay: Methodological and clinical aspects. Clin Biochem 21:63-68, 1988.

13. Elving LD, Bakkeren JAJM, Jansen MJH, De Kat Angelino CM, De Nobel E, Van Munster PJJ: Screening for microalbuminuria in patients with diabetes mellitus: Frozen storage of urine samples decreases their albumin content. Clin Chem 35:308-310, 1989. 
14. Tomaselli L, Trischitta V, Vinci C, Frittitta L, Squatrito S, Vigneri R: Evaluation of albumin excretion rate in overnight versus 24-b urine. Diabetes Care 12:585-587, 1989.

15. Osberg I, Chase HP, Garg SK, et al.: Effects of storage time and temperature on measurements of small concentrations of albumin in urine. Clin Chem 36:1428-1430, 1990.

16. Wiegmann TB, Chonko AM, Bernard MJ, et al.: Comparison of albumin excretion rate obtained with different times of collection. Diabetes Care 13:864-871, 1990.

17. Passing $\mathrm{H}$, Bablok $\mathrm{W}$ : A new biometrical procedure for testing the equality of measurements from two different analytical methods: Applica- tion of linear regression procedures for method comparison studied in clinical chemistry. J Clin Chem Clin Biochem 21:709-720, 1983.

18. Hayashi Y, Morikawa A, Makino M: Heterogeneity of urinary albumin from diabetic patients. Clin Chem Acta 190:93-104, 1990.

19. Ghiggeri GM, Candiano G, Delfino G, Bianchini F, Queirolo C: Glycosyl albumin and diabetic microalbuminuria: Demonstration of an altered renal handling. Kidney Int 25:565-570, 1984.

20. Ukita $C$, Nishikawa $M$, Shouzu A, Inada $M$ : Urinary excretion of glycated protein determined with a specific radioimmunoassay. Clin Chem 37:504-507, 1991 . 